\title{
The Phenomenon of Leprosy Stigma in the Continental United States*
}

\author{
Z. GUSSOW \\ Department of Psychiatry, Louisiana State University, \\ New Orleans, La., U.S.A \\ and \\ G. S. TRACY \\ Department of Sociology, Louisiana S'tate University, \\ Baton Rouge, La., U.S.A.
}

\begin{abstract}
Recent studies on leprosy stigma in the continental United States are presented and critically reviewed. In view of the strong concern about stigma expressed by patients and leprosy workers alike, it is interesting that strong public stigma has not been actually demonstrated scientifically. The evidence is equivocal; leprosy may be stigmatized to some extent, but so are other chronic diseases. The paper advances a social and psychological explanation for some of the more important peculiarities of the phenomenon of leprosy stigma, and concludes that those responsible for the treatment of patients may need to think in terms of alternatives to presumptions of public stigma.
\end{abstract}

\section{Introduction}

Reliable data on leprosy stigma in the continental United States are sparse. Some published reports by patients have provided some information, but such self-reports are subjective and often highly emotional. The other side of the picture, i.e., views of leprosy and leprosy patients by the public, is provided by a number of studies since 1955, although the specific objectives and methods employed have been quite varied. In general, available data, although of various degrees of reliability and validity, present a conundrum: health workers and potential employers feel that leprosy patients are stigmatized, although perhaps professional health workers do not make statements as strong as do non-professionals. Members of the public, on the other hand, seem much more neutral in their attitudes than many have believed. Further, patients report a rather wide variety of experiences, in some of which they were stigmatized, in others not. In this paper we present the available evidence, provide an evaluation of it, and suggest an explanation for some of the more important peculiarities of this phenomenon of leprosy stigma.

\section{Recent Studies of Stigma}

In 1959 Shearer and Hoodwin reported a "spot survey" of 149 nonprofessional and 55 professional workers in the California Department of Public

\footnotetext{
* Received for publication, 28 March, 1972.
} 
Health. Respondents' reactions to 14 statements such as: "All persons with leprosy should be isolated", "Would you mind working next to a person who had been treated for leprosy?" and "Would you mind waiting in a doctor's waiting-room with a patient with leprosy?" were analysed. "Responses of 80-90\% of the professional group were in accordance with accepted current medical knowledge" in most respects. The authors then contrasted responses of professionals to those of non-professionals to items in which professionals were below $80-90 \%$ affirmative (see Table 1). The authors summarized their findings with the statement " . . . the non-professional response seemed to be more closely associated with a general public viewpoint and the professional responses reflected the thinking of a high percentage of medical personnel". No evidence is given, however, on what the "general public viewpoint" is, although it is implied that it is quite negative. There is no description of how respondents were selected or of how representative of public health workers they might be. The paper is also largely admonitory rather than scientific.

TABLE 1

Percent affirmative responses to selected items by professionals and non-professionals (from Shearer and Hoodwin, 1959)

\begin{tabular}{lcc}
\hline \multicolumn{1}{c}{ Items } & Professionals & Non-professionals \\
\hline & $\%$ & $\%$ \\
Patients should not be isolated & 74 & 40 \\
Patients should be sent to Carville & 50 & 82 \\
Patients should be treated at home & 71 & 38 \\
It is all right for people being treated for & & 32 \\
\hline
\end{tabular}

A study of public attitudes about mental illness by Nunnally (1961) included an item on leprosy. The respondents were from an "opinion panel" of 400 people in central Illinois who are "an approximate miniature of the United States population in terms of education, sex ratio, income, religious affiliation and age". The questionnaire utilized the semantic differential scale developed by Osgood et al. (1957) for the analysis of connotations attached to concepts of various persons, objects, topics, or institutions. The technique asks respondents to rate subjects such as "an insane man", "someone with tuberculosis", "a leper" and the like on 16 seven-point scales in which a rating of 1 represents a very unfavourable view ("bad", "weak", "sad", etc.), while a rating of 7 indicates a positive concept ("good", "strong", "happy", etc.). A rating of 4 would be considered neutral. The 16 scales and average scores for the study are given in Table 2, as are results from a replicative study by Ebner (1968). The Nunnally average scores are based on responses of a panel of at least 50 judges carefully selected to be representative of the general public. The Ebner scores are based on 98 respondents in Baton Rouge; this is discussed later. The similarity of the mean scores is noteworthy. No statistical tests were employed because variances were not available for the Nunnally data. There are some discernible differences, however. For most scales the average scores for "leprosy" are lower than those for "a leper", which is probably indicative of less rejection of the person (leprosy patient) than of the condition. Particularly on those scales which are most 
TABLE 2

Average scale scores for leprosy on the semantic differential (from Nunnally, 1961; Ebner, 1968)

\begin{tabular}{lcc}
\hline \multicolumn{1}{c}{ Scale } & \multicolumn{2}{c}{ Average score } \\
& Nunnally (1961) & Ebner (1968) \\
\hline & “a leper" & "leprosy" \\
(1) Foolish-Wise & 4.26 & 3.78 \\
(2) Sad-Happy* & 2.48 & $*$ \\
(3) Passive-Active & 2.86 & 3.63 \\
(4) Insincere-Sincere & 5.17 & 4.39 \\
(5) Ignorant-Intelligent & 4.62 & 3.91 \\
(6) Unpredictable-Predictable & 4.38 & 3.24 \\
(7) Weak-Strong & 3.00 & 2.34 \\
(8) Slow-Fast & 3.07 & 3.24 \\
(9) Delicate-Rugged & 2.71 & 4.10 \\
(10) Cold-Warm & 4.21 & 3.87 \\
(11) Dirty-Clean & 4.02 & 3.52 \\
(12) Dangerous-Safe & 3.62 & 2.63 \\
(13) Tense-Relaxed & 3.26 & 3.15 \\
(14) Worthless-Valuable & 4.26 & 3.67 \\
(15) Sick-Healthy & 1.79 & 2.08 \\
(16) Bad-Good & 4.52 & 2.88 \\
\hline
\end{tabular}

* This scale was not included in Ebner's study.

pejorative are the Ebner averages lower-e.g., Dirty-Clean, Dangerous-Safe, Bad-Good. In any case, these data are not considered evidence of strong stigmatization of leprosy.

Barker (1964) further analysed Nunnally's data. He used the average score on each of the 16 scales as an observation and then calculated the product-moment correlation coefficient of each of the 20 subjects, pertinent to the illnesses used by Nunnally, with each other. A correlation coefficient of 1 indicates that the scale average for the two subjects being correlated tends to increase or decrease together, while a coefficient of zero indicates no systematic relationship in the scale scores for the two subjects. Barker found that the subject, "a leper", received semantic differential ratings significantly correlated with a number of other subjects (see Table 3). Barker concludes that "The popular concept of leprosy is almost identical with that of tuberculosis and is also related to concepts of other purely physical ailments and to that of nervous breakdown".

Ebner (1968) studied attitudes about leprosy relative to several other diseases in Baton Rouge, Louisiana, near the leprosarium at Carville. The sample consisted of one respondent from each of 130 randomly selected city blocks. Interviews were conducted in person and averaged $75 \mathrm{~min}$ in length. Most respondents either did not mention leprosy or did not consider it undesirable in answering an open-ended question, "What diseases or illnesses stand out in your mind as being the worst or least desirable?" Respondents were then presented with a prepared list of 10 diseases and asked to rank them from 10 to 1, i.e., from the worst disease to the least undesirable from purely medical considerations, then, later, from purely social or personal considerations. The mean rankings of the diseases by those respondents are given in Table 4 . It should be noted that leprosy does not change its relative position in the two sets of rankings, although those diseases 
TABLE 3

Correlation coefficients of "a leper" with other subjects (from Barker, 1964)

Someone with tuberculosis

Person who has cancer of lungs

0.96

Person with broken leg

Person with brain tumour

Someone who is dying from cancer and doesn't know it

Person who has recurrent attacks of malaria

Person who lost both eyes in an auto accident

Someone who was born blind

Someone with a stomach ulcer

Person with a nervous breakdown

Someone who lost eyesight because of severe case of syphilis
0.95

0.89

0.89

0.88

0.87

0.83

0.81

0.67

0.65

0.52

TABLE 4

Mean rankings by Baton Rouge respondents of indicated diseases on the basis of medical and social considerations (from Ebner, 1968)

\begin{tabular}{lcc}
\hline \multicolumn{1}{c}{ Disease } & $\begin{array}{c}\text { Medical } \\
\text { considerations }\end{array}$ & $\begin{array}{c}\text { Social } \\
\text { considerations }\end{array}$ \\
\hline Alcoholism & 1 & 8 \\
Arthritis & 4.5 & 1 \\
Cancer & 10 & 4 \\
Heart disease & 9 & 2 \\
Leprosy & 6 & 5.5 \\
Mental illness & 4.5 & 9.5 \\
Mental retardation & 2.5 & 7 \\
Poliomyelitis & 7.5 & 3 \\
Syphilis & 2.5 & 9.5 \\
Tuberculosis & 7.5 & 5.5 \\
\hline
\end{tabular}

often considered by the public to be socially undesirable but not medically serious reverse their positions-e.g., alcoholism, mental retardation, and syphilis. The equal ranking of 5.5 for leprosy and tuberculosis on social considerations reinforces Barker's conclusions noted above, namely that leprosy is seen as being similar to tuberculosis.

In the same study, a more intensive analysis was made on knowledge and attitudes about leprosy relative specifically to cancer and mental illness. In general, respondents exhibited least knowledge about leprosy, although there were some differences by social class and educational levels. The criterion employed for level of knowledge consisted of the information published by the National Association for Mental Health, the National Cancer Society and the United States Public Health Service Hospital at Carville, all generally available to the public. 
Attitudes toward leprosy relative to cancer and mental illness were measured for 98 respondents completing the scales through the use of the semantic differential, as in Nunnally's study, where the subjects to which the scales applied were "cancer", "leprosy", and "mental illness". When the totals for each of the 16 scales for each subject are summed and a mean attitude score calculated, leprosy and mental illness are found to tie with the same mean, 4.28 , while the mean for cancer is 4.10 . These means could hardly be considered different from each other on a 7-point scale, and they are all close to a neutral attitude value, 4.0 (Ebner, 1968).

An additional set of semantic differential scales incorporating connotations deemed particularly relevant to leprosy was also administered by Ebner to the same respondents for the same items; the scales and mean scores for mental illness, cancer and leprosy are compiled from Ebner's data and given in Table 5. The small differences between the highest means and the others on each scale must be considered. What is interesting is not that leprosy tends to be higher, but that it is so little higher than the others. Leprosy is strange, mysterious, contagious, and to be avoided, relative to mental illness and cancer, but not strongly so on this type of measure.

TABLE 5

Mean scores for respondents on indicated semantic differential scales for three diseases (from Ebner, 1968)

\begin{tabular}{lclll}
\hline & & & & \\
\cline { 2 - 3 } \multicolumn{1}{c}{ Scale } & Mental & & & \multicolumn{1}{c}{ Scale } \\
\hline Familiar & 5.16 & 3.97 & $5.72^{*}$ & Strange \\
Understandable & 4.75 & 4.47 & $4.98^{*}$ & Mysterious \\
Chronic & 4.56 & 3.78 & $4.63^{*}$ & Acute \\
Certain & $5.48^{*}$ & 4.66 & 4.57 & Uncertain \\
Beautiful & 4.41 & $5.21^{*}$ & 4.94 & Ugly \\
Sacred & $3.90^{*}$ & 3.67 & 3.81 & Profane \\
Approach & 4.18 & 4.56 & $5.04^{*}$ & Avoid \\
Family & 4.03 & 3.38 & $4.24^{*}$ & Outsider \\
Non-contagious & 2.79 & 3.04 & $5.22^{*}$ & Contagious \\
Hopeful & 2.76 & $3.46^{*}$ & 3.24 & Hopeless \\
Virtue & 3.87 & 3.89 & $3.98^{*}$ & Sin \\
Non-fatal & 3.24 & $5.16^{*}$ & 3.84 & Fatal \\
Reveal & 3.59 & 3.34 & $3.65^{*}$ & Conceal \\
Curable & 2.59 & $3.80^{*}$ & 3.17 & Incurable \\
Accept & 2.93 & 2.94 & $3.17^{*}$ & Reject \\
\hline
\end{tabular}

* Indicates highest average for that scale.

A more detailed analysis by Ebner, utilizing analysis of variance, indicates that anxiety, as measured by the semantic differential using all 30 scales, is higher for cancer and mental illness than it is for leprosy among women, Caucasians, the better educated, and the middle and upper classes. That leprosy is neither imminent nor salient to people in the United States, while cancer and mental illness are, might be a necessary and sufficient explanation for these findings.

In a study in 1968 by Moskal and Nolen, 188 respondents from Baton Rouge and Shreveport, Louisiana, indicated agreement on 21 declarative statements 
about characteristics of leprosy and other conditions and about people with these conditions. Supposedly a stratified random sample of households from these two cities, the sampling procedure was not appropriate and non-respondents were not evaluated, even though the overall response rate was only about $42 \%$ The study indicated no differences in attitudes about leprosy by city of residence, by social class, age, education or sex. On the other hand, Negroes seem to be more positive in their attitude than whites, and non-married people (generally younger) more positive than the married.

Since most respondents indicated a low positive or low negative attitude, there is no basis for asserting that strong stigma exists. Unfortunately, the authors give no analysis of leprosy relative to the other conditions they secured information about, making it difficult to establish the meaning of their study. Further, more powerful analytical techniques should have been employed.

Brown (1969) studied attitudes of health workers-physicians, nurses, nurse-aides, and social workers-toward leprosy relative to other conditions, namely nervous breakdown, diabetes, amputee, burns, tuberculosis and Von Tulow's neuroplasty (fictional). The health workers returned 80 mailed questionnaires out of the 279 sent out; 21 were returned out of 150 mailed to physicians, 26 out of 50 by nurses, 17 from nurse-aides, and 16 from 29 social workers. No analysis of bias due to non-returns is given.

The instrument (also used by Rolston and Chesteen, discussed below) presented a very short sketch of seven job applicants with one of each of the conditions noted. Each condition was then paired with every other, and the respondent was then asked to indicate the one of the pair less acceptable for employment and to give his reasons for rejecting the applicant. Six reasons for rejection were provided, and the respondent could use any or all of them. The reasons were: (1) possible increase in insurance costs; (2) fear of contagion for self or employees; (3) would make customers uncomfortable; (4) you really believe he is not capable of doing the work; (5) condition would not be acceptable to other employees; (6) condition might become worse.

Leprosy was consistently rejected by all four types of health workers. While there were some differences between types of workers in their reasons for rejection, the patterns here were also quite consistent. In order of frequency used, the principal reasons were: might make customers uncomfortable (No. 3), not acceptable to other employees (No. 5), danger of contagion (No. 2), condition might get worse (No. 6).

The structure of the study required the respondent to imagine how employers might feel; whether or not this taps the respondent's own feelings is debatable.

Rolston and Chesteen (1970) later employed the same instrument used by Brown in a study of employers in Louisiana. However, two additional names were used for leprosty-Hansen's disease, and "bacterial neurodermatitis"-and thus three different versions of the questionnaire, otherwise the same in all other respects, were mailed out. A total of almost 1600 questionnaires, about 533 of each version, were mailed over a period of a year. Although the returns were meagre $(17 \%)$, the authors believed that "... since the cumulative results remained constant with successive groups of returned forms ... we could validly project results from the smaller sample", that is from those returned. The authors found that regardless of which of the three names was used for it, leprosy always received the highest rejection rate by employers. On the other hand, the different names for the disease influenced the reasons for rejection of leprosy patients. The 
names "Hansen's disease" and "bacterial neurodermatitis" were almost identical in their patterns in reasons for rejection (see Table 6). For these two names, employers tended to be more concerned about the applicant as a person and about the customers; whereas for the name "leprosy" their concern was for the other employees and customers. The three highest ranking reasons for the three different disease names are in italic in Table 6.

TABLE 6

Percent distribution of reasons for rejection of the leprosy emplo yee applicant for the three disease terms used (from Rolston and Chesteen, 1970)

\begin{tabular}{|c|c|c|c|c|c|c|c|}
\hline \multirow{2}{*}{\multicolumn{2}{|c|}{ Reason }} & \multicolumn{2}{|c|}{ Leprosy } & \multicolumn{2}{|c|}{$\begin{array}{l}\text { Hansen's } \\
\text { disease }\end{array}$} & \multicolumn{2}{|c|}{$\begin{array}{c}\text { Bacterial } \\
\text { neurodermatitis }\end{array}$} \\
\hline & & Rank & $\begin{array}{l}\% \text { of } \\
\text { responses }\end{array}$ & Rank & $\begin{array}{l}\% \text { of } \\
\text { responses }\end{array}$ & Rank & $\begin{array}{l}\% \text { of } \\
\text { responses }\end{array}$ \\
\hline (1) & $\begin{array}{l}\text { You really believe he is not } \\
\text { capable of doing the work }\end{array}$ & 5 & 9.8 & I & 34.6 & 1 & 38.9 \\
\hline (2) & $\begin{array}{l}\text { Would make customers } \\
\text { uncomf ortable }\end{array}$ & 2 & 26.1 & 2 & 19.3 & 2 & 20.5 \\
\hline (3) & $\begin{array}{l}\text { Condition might become } \\
\text { worse }\end{array}$ & 4 & 11.5 & 3 & 16.6 & 3 & 18.5 \\
\hline (4) & $\begin{array}{l}\text { Condition would not be } \\
\text { acceptable to other employees }\end{array}$ & $I$ & 28.1 & 4 & 15.9 & 4 & 8.1 \\
\hline (5) & $\begin{array}{l}\text { Fear of contagion-self or } \\
\text { employees }\end{array}$ & 3 & 19.3 & 5 & 7.7 & 6 & 6.6 \\
\hline (6) & $\begin{array}{l}\text { Possible increase in } \\
\text { insurance costs }\end{array}$ & 6 & 5.2 & 6 & 5.9 & 5 & 7.5 \\
\hline
\end{tabular}

In general, the samples are suspect in most of these studies, although the studies by Ebner and Nunnally are probably acceptable because their procedures tended to deal with bias. But even in these cases, the samples are small. The other studies either used faulty sampling procedures, or the response rate was low, and no attempt was made to evaluate bias, although Rolston and Chesteen's variant of sequential sampling seemed to produce consistent results for employers.

In our view, the Nunnally, Ebner, and Barker studies do not demonstrate any strong leprosy stigma relative to other conditions; neither does the less acceptable study by Moskal and Nolen. Brown's study of health workers, and also that of Shearer and Hoodwin, seem to support the idea that non-professional health workers stigmatize leprosy more than do professional workers, but, aside from the question of sampling problems for both studies, it is not at all clear that Brown's respondents gave their own views. On the other hand, there may be a rather strong projection of stigma on to the public by Brown's respondents, such as we have implied for Shearer and Hoodwin and their non-professional respondents. Employers, however, seem to be afraid of presumed customer reaction-another projection.

In summary, we feel that the evidence from these studies is equivocal; leprosy may be stigmatized to some extent, but so are mental illness, cancer, tuberculosis, 
syphilis, etc. In view of the concern about such stigma expressed by not a few leprosy patients and leprosy workers, it is interesting that strong public stigma has not been actually scientifically demonstrated.

\section{Discussion}

Obviously the phenomenon of leprosy stigma is a complex one. A plausible explanation necessarily involves several dimensions on several social and psychological levels. Here we will allude to only a few of these. First, as is true for much attitude measurement in the social sciences, the measures employed may be either imprecise or unreliable, or unduly affected by the vagaries of mood and situation. The results of the semantic differential, however, have considerable face validity for conditions other than leprosy and we see no reason to reject them for leprosy. The high variability of respondents' attitudes was taken into consideration in Ebner's analysis, where leprosy does not compare unfavourably with mental illness and cancer-and with tuberculosis (Barker, 1964).

Second, in the United States, leprosy patients known to the staffs of treatment centres come largely from the lower income, lower educational, and less prestigious occupational categories: many of them are from minority groups (Rolston and Chesteen, 1970). In our experience the problems of coping, and of stigma, of these patients may be at least as much a consequence of their general level of social functioning as it is of the disease itself and especially if they are trying to function outside their usual social circles. Furthermore, in the United States with its social emphasis on physical comeliness, disfigurement and deformity, whatever their source, pose adaptive problems. When coupled with disability, there is additional jeopardy (Gussow and Tracy, 1969).

Another set of factors are contagion and strangeness; Ebner's study indicates that these are strong components in people's views of leprosy (see Table 5). Strangeness, of course, is a result of its low prevalence rate in the United States and higher prevalence in the non-Western world (Gussow and Tracy, 1970; Gussow and Tracy, 1971). Public concern with contagion, on the other hand, may be the result of the practice of isolating patients at certain stages, of the very existence of the leprosarium, and of the equivocal stance of medicine and public health about contagion (Gussow and Tracy, 1971). Concern with contagion does not necessary imply stigma, although the concern may be considerable, providing the aura of mystery is lifted from transmission and immunology.

The social institutionalization of leprosy treatment is another consideration. World-wide, since the middle of the 19th century, the staffs of most leprosy treatment centres have had strong religious affiliations, and this is still true today even in instances in which public health authorities have primary responsibility. The peculiar institutionalization of leprosy treatment has been discussed at length elsewhere (Gussow and Tracy, 1970, 1971). The principal social mechanisms involved in this institutionalization, in addition to the services of religious affiliates, are the isolation of patients in leprosaria and colonies, the isolation of the disease from secular modern medicine and, particularly in the United States, the special "ward status" of patients (Gussow and Tracy, 1971). In our view, then, there is a rather long-standing and pervasive premise about leprosy held by leprosy workers. Two strong components of this belief are, first, feelings that leprosy is stigmatized and that patients should be protected and, second, that 
leprosy could develop epidemic proportions, especially in "fresh" populations. The latter element derives from the standard epidemiological model of infectious diseases. Since the true epidemiology of leprosy is unknown and there are periodic leprosy alarms, the stance constitutes a defensive posture. The late 19th century panic about leprosy undoubtedly still influences thinking and attitudes, particularly for older leprosy workers.

A final point is that there does seem to be a "generation lag" in attitudes to leprosy. Many leprosy workers and the older members of the public express sentiments that are traditional in the sense indicated above. Young people, on the other hand, who tend to be better educated, seem to be more open and neutral about many things, including leprosy. This statement is buttressed by noting that a young patient from the United States Public Health Service Hospital at Carville, who was known to be from there, secured a degree in sociology at Louisiana State University and in his senior year was president of the Sociology Club. He was also instrumental in organizing several trips to the hospital.

A categorical, strong public stigmatization of leprosy has not been demonstrated. Those who are responsible for treating patients may have to think in terms of alternatives to presumptions of public stigma.

\section{References}

Barker, D. S. (1964). Concepts of disabilities. Personnel and Guidance Journal, 43, 371.

Brown, N. A. (1969). A survey of attitudes of certain medical and paramedical professionals toward Hansen's I)isease. M.S.W. thesis, School of Social Welfare, Louisiana State University, Baton Rouge.

Ebner, J. D. (1968). Community knowledge and attitudes about leprosy: A social-psychological study of the degree of stigmatization of a chronic disease. M.A. thesis, Department of Sociology, Louisiana State University, Baton Rouge.

Gussow, Z. and Tracy, G. S. (1969). Disability, disfigurement and stigma: A brief review. Combating Stigma Resulting from Deformity and Disease. New York: Leonard Wood Memorial for the Eradication of Leprosy.

Gussow, Z. and Tracy, G S. (1970). Stigma and the leprosy phenomenon: The social history of a disease in the nineteenth and twentieth centuries. Bull. Hist. Med. 44, 425.

Gussow, Z. and Tracy, G. S. (1971). The use of archival materials in the analysis and interpretation of field data: a case study in the institutionalization of the myth of leprosy as "leper". The American A nthropologist 73(3), 695.

Moskal, E. T. and Nolen, R. H. (1968). Social stratification as a factor in attitudes towards persons with Hansen's disease. M.S.W. thesis, School of Social Welfare, Louisiana State University, Baton Rouge.

Nunnally, J. C. (1961). Popular Conceptions of Mental Health. New York: Holt, Rinehart and Winston.

Osgood, C. E. (1957). The Measurement of Meaning. Urbana, Ill.: University of Illinois.

Rolston, R. H. and Chesteen, H. E. (1970). The Identification of Psychosocial Factors Related to the Rehabilitation of Leprosy Patients. Baton Rouge, Louisiana: School of Social Welfare, Louisiana State University.

Shearer, L. A. and Hoodwin, J. (1959). Hansen's disease-a modern approach. Int. J. Lepr. 27, 376. 